\title{
The kinase LRRK2 is differently expressed in chronic rhinosinusitis with and without nasal polyps
}

Yue Ma ${ }^{1,2}$, Chunquan Zheng ${ }^{1 *}$ (D) and Le Shi, ${ }^{1,2}$

\begin{abstract}
Background: Chronic rhinosinusitis (CRS), commonly divided into CRS with nasal polyps (CRSwNP) and without nasal polyps (CRSsNP) is an inflammatory disease which mechanism remain unclear. Leucine-rich repeat kinase 2 (LRRK2) has been proved to be a negative regulator of inflammation response while its role in pathogenesis of CRS has yet to be revealed. This research study was designed to investigate the relationship between the expression level and biologic role of LRRK2 in CRS.
\end{abstract}

Methods: Expression of LRRK2 mRNA and noncoding repressor of NFAT (NRON) were examined by qRT-PCR. Protein levels of LRRK2 were performed by western blot and immunohistochemistry. Nuclear factor of activated T cells (NFAT) nuclear translocation was analyzed by immunohistochemistry. Additionally, LRRK2 mRNA and NRON expression in response to specific inflammatory stimulation was measured in human nasal epithelia cells (HNECs).

Results: The expression of LRRK2 was increased in CRSsNP patients $(p<0.05)$ and positively correlated with the expression levels of CD3 and Charot-Leyden crystal. Meanwhile, the NRON expression level is much lower in CRSsNP patients compared to both the control group and CRSwNP group $(p<0.05)$. Marked enhanced NFAT nuclear localization was observed in CRSwNP groups compared with the CRSsNP and control group $(p<0.0001)$. And the overexpression of LRRK2 was significantly regulated by lipopolysaccharide (LPS) in HNECs $(p<0.05)$. Moreover, IL-17A can increase LRRK2 expression and suppress NRON expression in vitro and dexamethasone can rescue the NRON inhibition.

Conclusion: LRRK2 and NRON may play different role in CRSsNP and CRSWNP. The molecular mechanisms identified here may aid in the design of novel therapeutic strategies to improve clinical outcomes.

Keywords: LRRK2, NRON, Long non-coding RNA, Chronic rhinosinusitis, Pro-inflammatory cytokine

\section{Background}

In general, chronic rhinosinusitis (CRS) is an inflammatory disease that is composed of CRS with nasal polyps (CRSwNP) and without nasal polyps (CRSsNP). Although their pathogenesis is not yet clear, it is commonly acknowledged that the two types of CRS possess distinct inflammation and remodeling patterns [1, 2]. CRSsNP is characterized by Th1-biased inflammation

\footnotetext{
*Correspondence: zheng_ent96@163.com

${ }^{1}$ Department of Otolaryngology-Head and Neck Surgery, Eye Ear Nose and Throat Hospital, Fudan University, 83 Fenyang Road, Xuhui District, Shanghai 200031, People's Republic of China

Full list of author information is available at the end of the article
}

and an elevated expression of transforming growth factor (TGF- $\beta 1$ ), while CRSwNP is characterized by a Th2biased inflammation [3]. Meanwhile, the dysregulation of innate immunity has been regarded as the key point for the initiation and perpetuation of inflammatory responses in CRS patients [4]. The toll-like receptor signaling pathway induced by lipopolysaccharide (LPS)has been reported as one of critical factors in the pathogenesis of CRS, but the mechanism remains unclear. Thus, there is an urgent need for a new biomarker that can further explain this mechanism.

Leucine-rich repeat kinase 2 (LRRK2), also known as Dardarin, is a large complex protein that contains several 
domains [5-7]. Accumulating evidence has revealed that LRRK2 is involved in regulating inflammatory processes [8-10]. Participation in the signaling of IFN- $\gamma[11,12]$, enhancement of NF-kB-dependent transcription, and interference in reactive oxygen species (ROS) production all indicate that LRRK2 may play a pivotal role in the anti-microbial process [11].

It has already been identified that LRRK2 negatively regulates NFAT by interacting with NRON, a known repressor of NFAT. Long non-coding RNA (lncRNA) NRON and 11 additional proteins, including LRRK2, constitute a protein-RNA complex which could directly inhibit the translocation of NFAT to the nucleus $[13,14]$ such that cell activation and the proceeding immune reactivity are suppressed. For example, enhanced nuclear location of NFAT was associated with more severe colitis in LRRK2-deficient mice [14].

Therefore, LRRK2 is a negative regulator of this inflammation response. These findings implied that the changes in LRRK2 expression levels resulting from extrinsic signals may play a vital role in the regulation of immune responses. However, the role of LRRK2 in the pathogenesis of CRS has yet to be revealed. Our present study was designed to investigate the relationship between the expression level and biologic role of LRRK2 in CRS.

\section{Methods}

\section{Subjects}

The subjects $(\mathrm{n}=74)$ were all recruited from the Department of Otolaryngology-Head and Neck Surgery, Eye, Ear, Nose, and Throat Hospital, Fudan University. All were CRS patients who had not taken oral and/or topical corticosteroids or any other sinonasal medications for at least 1 month prior to the study and were diagnosed based on previously published criteria [15]. NPs were obtained from CRSwNP patients $(\mathrm{n}=34)$, and nasal mucosa of middle turbinates were from CRSsNP patients $(n=23)$. At the same time, the nasal mucosa of inferior turbinates were collected from those patients $(n=17)$ who had no clinical symptoms or radiographic evidence of CRS and who underwent a septoturbinoplasty. Patients responding positively to a skin-prick test were diagnosed with an allergy. All of the patients' clinical data are presented in Table 1 . The exclusion criteria for the study group ran as follow: age $<18$ or $>80$ years, a diagnosis of cystic fibrosis, Churg-Strauss syndrome, immunodeficiency, or autoimmune disease.

This study obtained permission from the local ethical committee of the Otolaryngology-Head and Neck Surgery, Eye, Ear, Nose, and Throat Hospital, Fudan University, and informed consent was signed by every subject.

\section{RNA extraction and real-time polymerase chain reaction} Total RNA was extracted using TRIzol reagent (Invitrogen) according to the manufacturer's instructions. Then, PrimeScript RT master mix (Takara) was used to synthesize complementary DNA (cDNA). An ABI 7900 Sequence Detection System (ABI) was used to perform qRT-PCR with SYBR Green chemistry. Table 2 showed the primers (Sangon Biotech). The expression of each gene was calculated using the comparative threshold cycle $\left(2^{-\Delta \Delta C T}\right)$ method.

\section{Immunohistochemistry (IHC) staining}

Immunohistochemistry was performed following the protocol for the streptavidin-biotin complex (SABC) kit (Weiao Biological Technology). The sections were incubated with primary antibody (polyclonal rabbit

Table 1 Characteristics of included subjects

\begin{tabular}{llll}
\hline & Control subjects & Patients with CRSsNP & Patients with CRSwNP \\
\hline No. of patients & 17 & 23 & 34 \\
Sex, male/female & $12 / 5$ & $12 / 11$ & $20 / 14$ \\
Age (years), mean (SD) & $36(8)$ & $52(17)$ & $37(13)$ \\
Atopy, no. & 0 & 4 & 6 \\
Asthma, no. & 0 & 0 & 2 \\
Aspirin intolerance, no. & 0 & 0 & 0 \\
Smoking, no. & 0 & 10 & 16 \\
Operation history, no. & 0 & 0 & 2 \\
Methodologies used & & 16 & 25 \\
Tissue IHC & 10 & 21 & 30 \\
Tissue mRNA & 15 & 9 & 9 \\
Tissue western blot & 9 & & \\
\hline
\end{tabular}


Table 2 Primers

\begin{tabular}{lll}
\hline Name & Sense & Antisense \\
\hline GAPDH & CAAGGTCATCCATGACAACTT & GTCCACCACCCTGTTGCTGTAG \\
& TG & \\
LRRK2 & GGATGTTGGTGATGGAGTT & GGCTGAGTGGAGGTATCT \\
NRON & AACAACCCAGCAAGGGAAGT & AAGAGCATGAACGCACATCCT \\
& AG & AG \\
CD3 & TAGAGGAACTTGAGGACAGA & GCAGAGTGGCAATGACAT \\
Tryptase & TCTGAAGCAGGTGAAGGT & AGTCCAAGTAGTAGGTGACA \\
CLC & TTGTCTACTGGTTCTACTGT & CAATGTCTGATTCCTCCTTC \\
CXCR1 & ATGCTGTTCTGCTATGGATT & CGATGAAGGCGTAGATGAT \\
CD68 & CTCCAGCAGAAGGTTGTC & TGATGAGAGGCAGCAAGA \\
\hline
\end{tabular}

anti-human LRRK2; Abcam; 1:200 dilution; polyclonal goat anti-human NFAT1; Abcam; 1:100 dilution) at $4{ }^{\circ} \mathrm{C}$ overnight. 3'3-Diaminobenzidine (DAB) was used for the final visualization. To analyze LRRK2 expression, two pathologists scored the results independently according to the immunostaining intensity scale, which ran as follows: $0=$ absent; $1=$ mild; $2=$ moderate; and $3=$ marked. The numbers of immuno-positive cells within the samples were also counted in at least five random areas at a $400 \times$ magnification, and at the same time, the percentage of immuno-positive cells was scored according to the standard scale as follows: $0(0-9 \%) ; 1(10-25 \%) ; 2$ (26-50\%); 3 (51-75\%); and 4 (>76\%). Multiplication of the two abovementioned scores provided the final score for each sample. The highest final score was 12 while the lowest was 0 . To analyze NFAT nuclear translocation, the percentage of cells with NFAT1 nuclear staining in all immuno-positive cells were also counted in five random areas at a 400x magnification.

\section{Western blots}

Protein samples $(30 \mu \mathrm{g})$ were separated by electrophoresis using $10 \%$ sodium dodecyl sulfate polyacrylamide gels and then transferred to polyvinylidene difluoride (PVDF) membranes for incubation with anti-LRRK2 (Abcam; 1:1000) antibody. Image J (NIH) analysis and processing software was used to quantify data, which was expressed as densitometry units (DU). The expression of $\beta$-actin (Abcam; 1:1000) was regarded as an internal reference.

\section{Cell culture and stimulation}

Following a previously established protocol, HNECs (Human Nasal Epithelia Cells) isolated from the middle turbinates of CRSsNP patients were cultured [16]. Briefly, nasal specimens were immersed in DMEM/F12 media (Hyclone) containing $1.4 \mathrm{mg} / \mathrm{ml}$ protease $\mathrm{K}$ and $0.1 \mathrm{mg} /$ $\mathrm{ml}$ DNase for a $1.5 \mathrm{~h}$ incubation at $37{ }^{\circ} \mathrm{C}$. Next, all cells were collected and immersed in DMEM/F12 (Hyclone) containing $1 \%$ ITS for $2 \mathrm{~h}$ at $37{ }^{\circ} \mathrm{C}$ before being cultured in BEGM medium (Lonza).

When $80-90 \%$ confluence was reached, fresh media without hydrocortisone was added in the presence of the following stimulators or control PBS for $12 \mathrm{~h}$ : the recombinant cytokines human IFN- $\gamma(100 \mathrm{ng} / \mathrm{mL}), \mathrm{IL}-4$ (100 ng/mL), IL-13 (100 ng/mL), IL-17A (100 ng/mL), TGF- $\beta$ (10 ng/mL), and IL-1 $\alpha(100 \mathrm{ng} / \mathrm{mL}$; all purchased from Peprotech); the TLR agonists LPS (500 ng/mL, from Escherichia coli serotype 0111: B4; purchased from Sigma) and the glucocorticoid dexamethasone (Sigma; $10 \mu \mathrm{g} / \mathrm{mL})$. After stimulation, HNECs were collected for qRT-PCR analysis.

\section{Statistical analysis}

Statistical analyses were performed by SPSS v22.0 software (IBM Corporation). The data were presented as medians and interquartile ranges. Tests for Gaussian distribution were performed by Kolmogorov-Smirnov test. Differences between groups were evaluated by one-way analysis of variance and either by the two independent sample $t$ test or the Mann-Whitney $U$ test. The correlation analysis was performed to assess the correlation between two groups by Spearman's rank correlation. $p<0.05$ was regarded as statistically significant.

\section{Results \\ NRON and LRRK2 mRNA levels in nasal tissues}

As showed in Fig. 1a, significant upregulation of LRRK2 mRNA levels was found in CRSsNP groups but not in CRSwNP groups compared with the control group $(p<0.0001)$, and NRON levels were significantly higher in the inferior turbinate than in the middle turbinate of CRSsNP groups $(p<0.0001)$ and in NPs $(p<0.01)$ (Fig. 1b).

\section{LRRK2 protein levels in nasal tissues}

To verify the results at the protein level, western blots were performed. Strong bands for LRRK2 were observed in CRSsNP groups, whereas weak bands were found in the CRSwNP group and in the control group (Fig. 1c). The LRRK2 protein level was significantly higher in the CRSsNP group than in the CRSwNP group and the control group (Fig. 1d; $p<0.0001$ ).

\section{LRRK2 and NFAT immunoreactivity in nasal tissues}

Immunohistochemistry was performed to further confirm the results pertaining to the protein levels of LRRK2 in the various samples. As depicted by immunohistochemistry staining (Fig. 2a-c), LRRK2 was significantly overexpressed in the CRSsNP group compared with the control group and CRSwNP group. The cytoplasmic or nuclear staining of LRRK2 was mainly located at the 


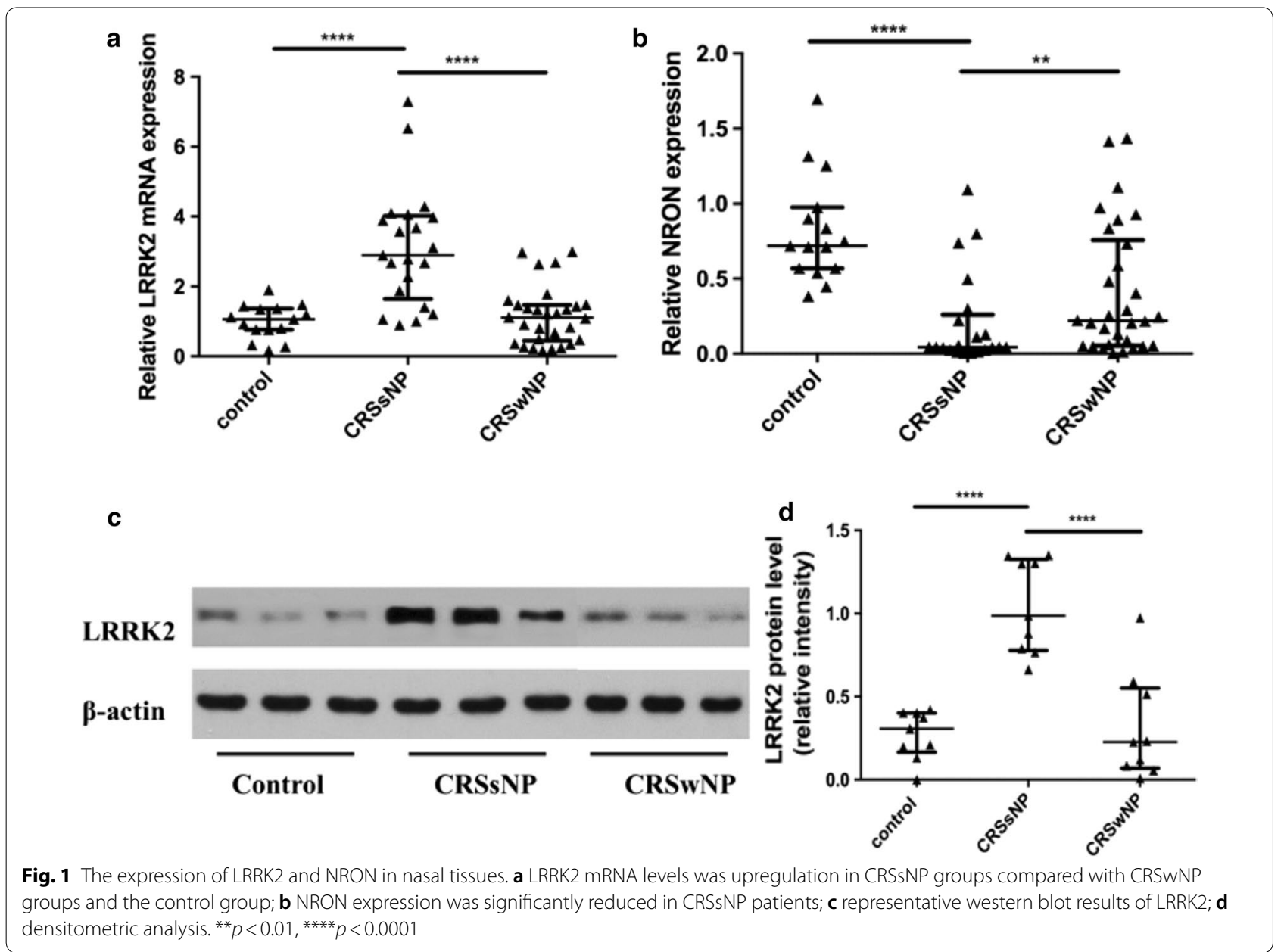

nasal epithelium and in submucosal inflammatory cells. In comparison with control groups and NPs, quantitative analysis of LRRK2 revealed an obvious elevation in immuno-labeling of LRRK2 in the CRSsNP group (Fig. 2d; $p<0.01$ ). NFAT nuclear translocation was also detected by immunohistochemistry (Fig. 2e-g). Marked enhanced NFAT nuclear localization was observed in CRSwNP groups compared with the CRSsNP group and control group (Fig. 2h; $p<0.0001$ ).

\section{Detection of LRRK2 producing cells in nasal mucosa}

These results revealed that LRRK2+ cells were highly accumulated in the submucosal region of CRSsNP tissues and that the mRNA and protein expression levels of LRRK2 were also significantly higher in CRSsNP tissues (Fig. 2). Next, the expression of LRRK2 and the markers of inflammatory cells in CRSsNP were assessed by qRTPCR and the relationship between these markers were analyzed by Spearman's rank correlation. The results demonstrated that the mRNA expression levels of LRRK2 in CRSsNP tissue were significantly and positively related to the expression of CD3 $(\mathrm{r}=0.7286 ; p=0.0029)$,
Charot-Leyden crystal (CLC; $\mathrm{r}=0.5712 ; p=0.0284$ ), CD68 ( $r=0.146 ; p<0.05)$, but not CXCR1, tryptase and CD68, which indicated that the expression of LRRK2 may derive from $\mathrm{T}$ cells, eosinophils (Fig. 3).

LPS and pro-inflammatory cytokines differentially regulate LRRK2 and NRON expression in human nasal epithelial cells (HNECs) in vitro

To further expose the role and mechanism of the LRRK2 signaling pathway in the nasal mucosa of CRS, the effects of TLR activation and pro-inflammatory cytokine stimulation were examined in cultured human nasal epithelial cells. As presented in Fig. 4a, mRNA expression levels of LRRK2 were significantly increased after stimulating the HNECs with LPS, the TLR agonists $(p<0.001)$. Meanwhile, stimulation with IL-17A increased very low LRRK2 mRNA expression $(p<0.01)$ compared with stimulation by the other pro-inflammatory cytokines, including IFN$\gamma$, IL-4, IL-13, IL- $1 \alpha$, and TGF- $\beta$ which also increased LRRK2 expression $(p<0.01)$. In contrast, NRON levels were significantly inhibited by stimulation with IL-17A $(p<0.001$; Fig. 4b). 

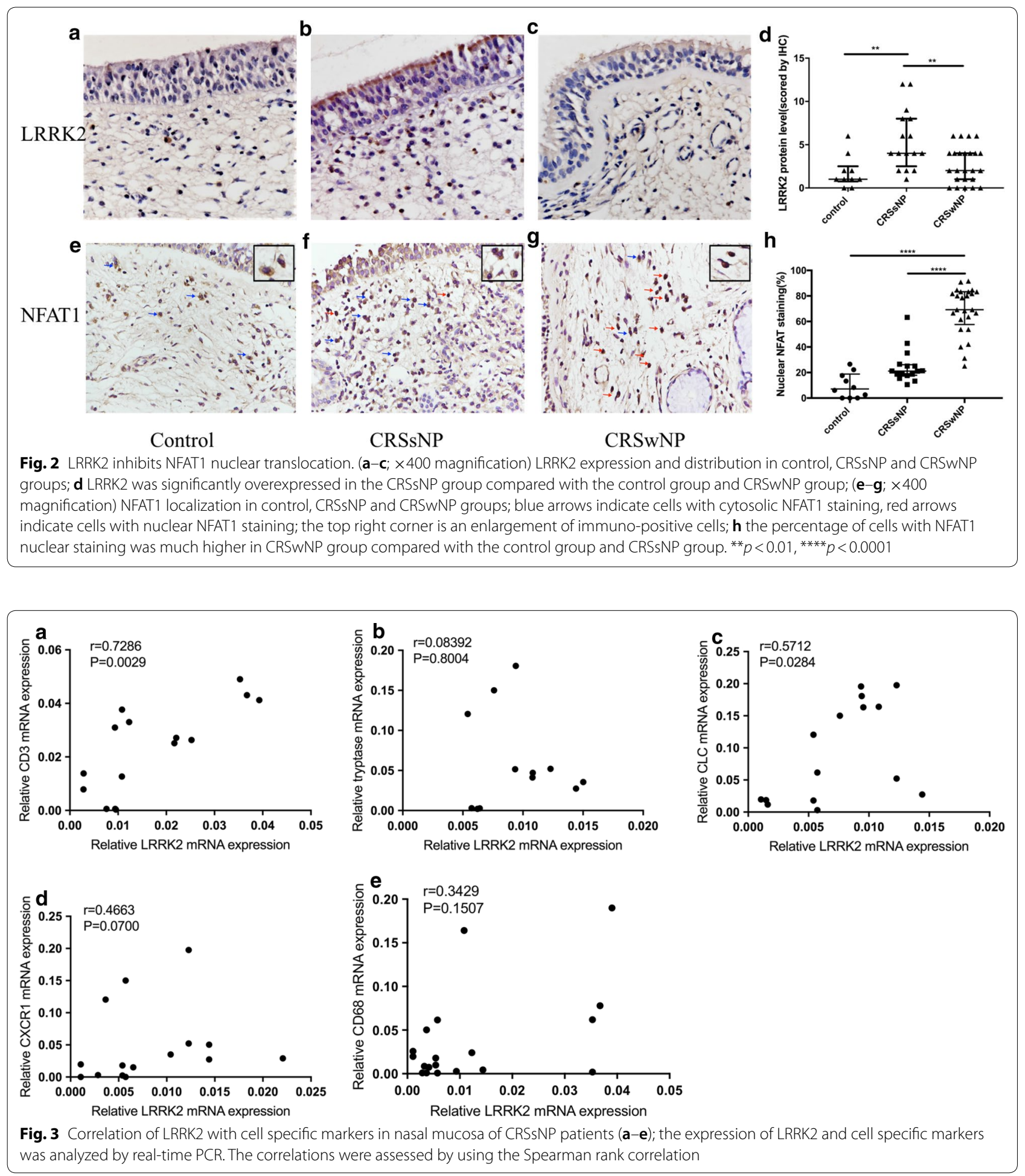

\section{Glucocorticoid treatment increases LRRK2 expression in vitro}

Because glucocorticoid treatment is recommended as one of the primary treatment of choice for patients with
CRS, the effect of glucocorticoids on LRRK2 mRNA and NRON expression in HNECs was examined. After incubating cells with dexamethasone, LRRK2 mRNA and NRON expression was more upregulated in the presence 

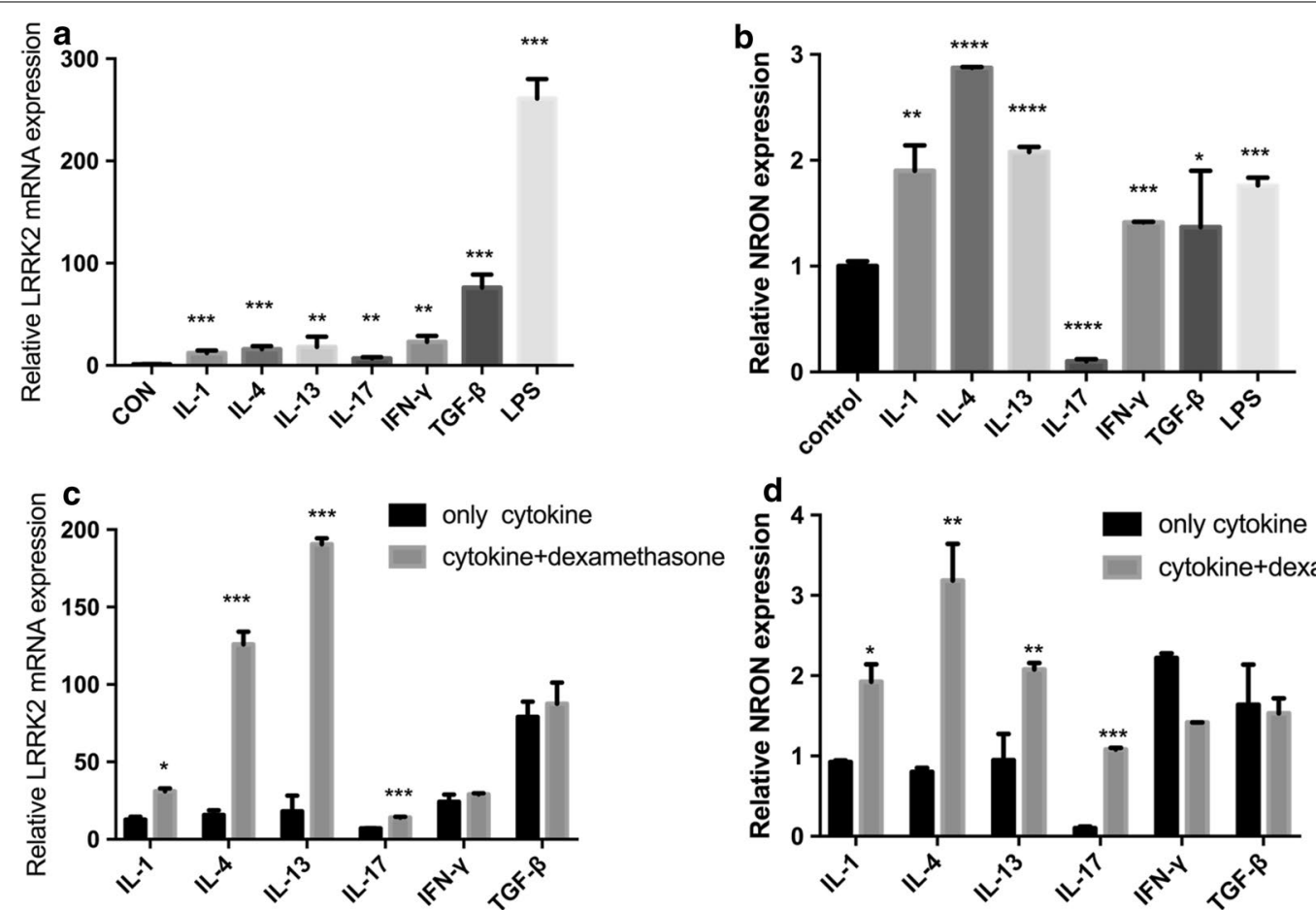

Fig. 4 LRRK2 $m R N A$ and NRON expression in cultured HNECs in response to pro-inflammatory cytokines, LPS and dexamethasone. a LRRK2 mRNA, b NORN expression after a $12 \mathrm{~h}$ stimulation; c LRRK2 mRNA, d NORN expression after pro-inflammatory cytokines stimulation with or without dexamethasone. Results represent mean values from 3 independent experiments. Data are expressed as means (SEMs). ${ }^{*} p<0.05,{ }^{* *} p<0.01$, ${ }^{* * *} p<0.001,{ }^{* * * *} p<0.0001$

of pro-inflammatory cytokines (IL-17A, IL-4, IL-13, IL- $1 \alpha ; p<0.05)$ than without dexamethasone stimulation (Fig. 4c, d). In contrast, NRON expression was lower when the cells were stimulated with IFN- $\gamma$ plus dexamethasone compared to only IFN- $\gamma$ stimulation.

\section{Discussion}

This study demonstrated that the expression of LRRK2 was increased in patients suffering from CRSsNP (Figs. 1, 2 ), and the over-expression of LRRK2 was regulated by LPS in HNECs (Fig. 4). Moreover, LRRK2 expression in CRSsNP tissues was correlated with the expression levels of CD3, CLC, and CD68, which suggested that T cells, eosinophils, and macrophages may be the main LRRK2-producing cells in nasal mucosa (Fig. 3). Meanwhile, NRON expression level is much lower in CRSsNP patients compared to both the control group and CRSwNP group (Fig. 1). Its expression can be strongly suppressed by stimulation with IL-17A in vitro, and dexamethasone can rescue this phenomenon.

CRS, commonly divided into CRSwNP and CRSsNP, is characterized by chronic inflammation of the paranasal sinuses. Due to the poor awareness of the initiation and progression of CRS, the development of effective treatments for this disease remains stagnant [17]. LRRK2 can be physically associated with NRON and this proteinRNA complex has been proven to be a NFAT suppressor in many inflammatory diseases such as inflammatory bowel disease [18], and LRRK2 deficiency can lead to a more serious inflammation response. In the results presented herein, considerable data indicates that the upregulation of LRRK2 expression in CRSsNP is obviously higher than in the CRSwNP group, and the percentage of cells with NFAT nuclear staining in CRSsNP is much lower in CRSwNP group (Fig. 2), which suggests that a lower expression of LRRK2 exhibits less of an inhibitory effect on NFAT. Moreover, this data supports that the idea that the defection of innate immunity may lead to a robust adaptive immune response, which triggers the generation of pro-inflammatory cytokines and the development of chronic inflammation [19].

NRON is a cytoplasmic lncRNA which has previously been reported to be highly expressed in human immune cells including macrophages, dendritic cells, and neutrophils along with its vital role in $\mathrm{T}$ cell cytokine production. NRON acts as a scaffold to maintain the structure of a ribonucleoprotein complex which can retain the transcription factor NFAT in the cytoplasm [13], meaning that NRON plays a significant role in the immune response. However, in this study, the expression level of 
NRON is lower in CRSsNP group, which indicates that in the RNA-protein complex, LRRK2 may play a much more important role in the generation and the development of CRS than NRON.

Within the immune system, the expression of LRRK2 has been reported in lymphocytes, dendritic cells, and macrophages [11]. In this study, LRRK2-producing cells were identified in CRSsNP nasal mucosa. Considerable data had already shown that $\mathrm{T}$ cells and eosinophils may be the main LRRK2-producing cells in CRSsNP nasal mucosa, which was in line with the published reports.

It has also been reported that the induction of LRRK2 expression could be triggered in mouse bone marrowderived macrophages under the stimulation of toll-like receptor 4 [20], whereas opposite findings were issued in another study [14]. Hence, to further explore the mechanism of LRRK2 and NRON expression in CRS, HNECs were incubated with LPS and pro-inflammatory cytokines (IFN- $\gamma$, TGF- $\beta$, IL-1 $\alpha$, IL-4, IL-13, IL-17A). The results showed that IL-17A can increase LRRK2 and suppress NRON expression which were coincidence with the expression of LRRK2 and NRON in nasal mucosa of CRSsNP patients, while other cytokines can induce both LRRK2 and NRON. The results indicate that IL-17A may play a significant role in the LRRK2 signaling pathway in CRSsNP patients, while both Th1 and Th 2 cytokines participate in the inflammation activities of CRSsNP nasal mucosa. Further studies are urgently needed to confirm this theory.

Notably, this study found that dexamethasone universally enhanced the induced role of pro-inflammatory cytokines (IL-13, IL-1 $\alpha$, IL- 4 ) in LRRK2 mRNA and NRON expression. What's more, it can rescue IL-17A cytokine-induced NRON suppression. Although the underlying molecular mechanisms require further characterization, this finding demonstrates that glucocorticoid treatment can make more LRRK2-NRON complex so that it can play a more significant role in the inhibition of NFAT translocation. Then, the inflammation response will be inhibited.

\section{Conclusions}

In summary, it has been revealed here that LRRK2 is elevated in patients with CRSsNP, while NRON is lower in this group. LRRK2 can strongly inhibit the nuclear function of NFAT. IL-17A may play a significant role in the LRRK2 signaling pathway in CRSsNP patients. Further investigation will concentrate on the interaction of LRRK2 and NRON in CRS to reveal their effects on inflammation and the immune system. The molecular mechanisms identified here will help clarify the pathogenic processes involved in these two CRS subsets, as well as aid in the design of novel therapeutic strategies to improve clinical outcomes.

\section{Abbreviations}

CRS: chronic rhinosinusitis; LPS: lipopolysaccharide; LRRK2: leucine-rich repeat kinase 2; NRON: noncoding repressor of NFAT; NFAT: nuclear factor of activated T cells; ROS: reactive oxygen species; IncRNA: long non-coding RNA; IHC: immunohistochemistry; SABC: streptavidin-biotin complex; PVDF: polyvinylidene difluoride; DU: densitometry units; HNECs: human nasal epithelia cells; CLC: Charot-Leyden crystal.

\section{Authors' contributions \\ Yue Ma performed most of the experiment and was a major contributor in writing the manuscript. Chunquan Zheng designed the experiment and analyzed the results. Le Shi collected all the specimens and participant in the experiment. All authors read and approved the final manuscript.}

\section{Author details}

${ }^{1}$ Department of Otolaryngology-Head and Neck Surgery, Eye Ear Nose and Throat Hospital, Fudan University, 83 Fenyang Road, Xuhui District, Shanghai 200031, People's Republic of China. ${ }^{2}$ Shanghai Key Clinical Disciplines of Otorhinolaryngology, Shanghai, People's Republic of China.

\section{Acknowledgements}

Not applicable.

\section{Competing interests}

The authors declare that they have no competing interests.

\section{Availability of data and materials}

All data generated or analysed during this study are included in this published article.

\section{Consent for publication}

Not applicable.

\section{Ethics approval and consent to participate}

All procedures performed in studies involving human participants were in accordance with the ethical standards of the institutional and/or national research committee and with the 1964 Helsinki declaration and its later amendments or comparable ethical standards. Informed consent was obtained from all individual participants included in the study This study obtained permission from the local ethical committee of the OtolaryngologyHead and Neck Surgery, Eye, Ear, Nose, and Throat Hospital, Fudan University.

\section{Funding}

This work was supported by grants from the National Natural Science Foundation of China (Nos.81470672).

\section{Publisher's Note}

Springer Nature remains neutral with regard to jurisdictional claims in published maps and institutional affiliations.

Received: 31 October 2017 Accepted: 28 February 2018

Published online: 12 March 2018

\section{References}

1. Stevens WW, Lee RJ, Schleimer RP, Cohen NA. Chronic rhinosinusitis pathogenesis. J Allergy Clin Immunol. 2015;136:1442-53. https://doi. org/10.1016/j.jaci.2015.10.009.

2. Van Zele T, Claeys S, Gevaert P, Van Maele G, Holtappels G, Van Cauwenberge $P$, Bachert $C$. Differentiation of chronic sinus diseases by measurement of inflammatory mediators. Allergy. 2006;61:1280-9. https://doi.org /10.1111/j.1398-9995.2006.01225.x.

3. Van Bruaene N, Derycke L, Perez-Novo CA, Gevaert P, Holtappels G, De Ruyck N, Cuvelier C, Van Cauwenberge P, Bachert C. TGF-beta signaling 
and collagen deposition in chronic rhinosinusitis. J Allergy Clin Immunol. 2009;124:253-9. https://doi.org/10.1016/j.jaci.2009.04.013.

4. Kern RC, Conley DB, Walsh W, Chandra R, Kato A, Tripathi-Peters A, Grammer LC, Schleimer RP. Perspectives on the etiology of chronic rhinosinusitis: an immune barrier hypothesis. Am J Rhinol. 2008;22:549-59. https:// doi.org/10.2500/ajr.2008.22.3228.

5. Paisan-Ruiz C, Jain S, Evans EW, Gilks WP, Simon J, van der Brug M, Lopez de Munain A, Aparicio S, Gil AM, Khan N, Johnson J, Martinez JR, Nicholl $D$, et al. Cloning of the gene containing mutations that cause PARK8-linked Parkinson's disease. Neuron. 2004;44:595-600. https://doi. org/10.1016/j.neuron.2004.10.023.

6. Zimprich A, Biskup S, Leitner P, Lichtner P, Farrer M, Lincoln S, Kachergus J, Hulihan M, Uitti RJ, Calne DB, Stoessl AJ, Pfeiffer RF, Patenge N, et al. Mutations in LRRK2 cause autosomal-dominant parkinsonism with pleomorphic pathology. Neuron. 2004;44:601-7. https://doi.org/10.1016/j.neuro n.2004.11.005.

7. Meylan E, Tschopp J. The RIP kinases: crucial integrators of cellular stress. Trends Biochem Sci. 2005;30:151-9. https://doi.org/10.1016/j. tibs.2005.01.003.

8. Russo I, Bubacco L, Greggio E. LRRK2 and neuroinflammation: Partners in crime in Parkinson's disease? J Neuroinflamm. 2014;11:52. https://doi. org/10.1186/1742-2094-11-52.

9. Dzamko N, Halliday GM. An emerging role for LRRK2 in the immune system. Biochem Soc Trans. 2012;40:1134-9. https://doi.org/10.1042/bst20 120119.

10. Mamais A, Cookson MR. LRRK2: dropping (kinase) inhibitions and seeking an (immune) response. J Neurochem. 2014;129:895-7. https://doi. org/10.1111/jnc.12691.

11. Gardet A, Benita Y, Li C, Sands BE, Ballester I, Stevens C, Korzenik JR, Rioux JD, Daly MJ, Xavier RJ, Podolsky DK. LRRK2 is involved in the IFN-gamma response and host response to pathogens. J Immunol. 2010;185:5577-85. https://doi.org/10.4049/jimmunol.1000548.

12. Kuss M, Adamopoulou E, Kahle PJ. Interferon-gamma induces leucinerich repeat kinase LRRK2 via extracellular signal-regulated kinase ERK5 in macrophages. J Neurochem. 2014;129:980-7. https://doi.org/10.1111/ jnc.12668.
13. Willingham AT, Orth AP, Batalov S, Peters EC, Wen BG, Aza-Blanc P, Hogenesch JB, Schultz PG. A strategy for probing the function of noncoding RNAs finds a repressor of NFAT. Science. 2005;309:1570-3. https://doi. org/10.1126/science.1115901.

14. Liu Z, Lee J, Krummey S, Lu W, Cai H, Lenardo MJ. The kinase LRRK2 is a regulator of the transcription factor NFAT that modulates the severity of inflammatory bowel disease. Nat Immunol. 2011;12:1063-70. https://doi. org/10.1038/ni.2113.

15. Rosenfeld RM, Piccirillo JF, Chandrasekhar SS, Brook I, Kumar KA, Kramper M, Orlandi RR, Palmer JN, Patel ZM, Peters A, Walsh SA, Corrigan MD. Clinical practice guideline (update): adult sinusitis executive summary. Otolaryngol Head Neck Surg. 2015;152:598-609. https://doi.org/10.1177/01945 99815574247.

16. Wang H, Bai J, Ding M, Liu W, Xu R, Zhang J, Shi J, Li H. Interleukin-17A contributes to the expression of serum amyloid $A$ in chronic rhinosinusitis with nasal polyps. Eur Arch Otorhinolaryngol. 2013;270:1867-72. https ://doi.org/10.1007/s00405-012-2295-X

17. Fokkens WJ, Lund VJ, Mullol J, Bachert C, Alobid I, Baroody F, Cohen N, Cervin A, Douglas R, Gevaert P, Georgalas C, Goossens H, Harvey R, et al. EPOS 2012: European position paper on rhinosinusitis and nasal polyps 2012. A summary for otorhinolaryngologists. Rhinology. 2012;50:1-12. https://doi.org/10.4193/Rhino50E2.

18. Liu Z, Lenardo MJ. The role of LRRK2 in inflammatory bowel disease. Cell Res. 2012;22:1092-4. https://doi.org/10.1038/cr.2012.42.

19. Tieu DD, Kern RC, Schleimer RP. Alterations in epithelial barrier function and host defense responses in chronic rhinosinusitis. J Allergy Clin Immunol. 2009;124:37-42. https://doi.org/10.1016/j.jaci.2009.04.045.

20. Hakimi M, Selvanantham T, Swinton E, Padmore RF, Tong Y, Kabbach G, Venderova K, Girardin SE, Bulman DE, Scherzer CR, LaVoie MJ, Gris D, Park DS, et al. Parkinson's disease-linked LRRK2 is expressed in circulating and tissue immune cells and upregulated following recognition of microbial structures. J Neural Transm (Vienna). 2011;118:795-808. https://doi. org/10.1007/s00702-011-0653-2.

\section{Submit your next manuscript to BioMed Central and we will help you at every step:}

- We accept pre-submission inquiries

- Our selector tool helps you to find the most relevant journal

- We provide round the clock customer support

- Convenient online submission

- Thorough peer review

- Inclusion in PubMed and all major indexing services

- Maximum visibility for your research

Submit your manuscript at www.biomedcentral.com/submit 